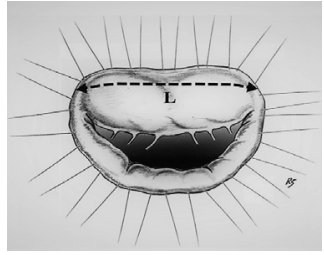

\section{A RIGHT TRACK \\ STEMS FROM THE RIGHT LEARNING}

\section{To the Editor:}

Wan and Hu's commentary ${ }^{1}$ on our work ${ }^{2}$ is notable; however, some points need clarification. The geometric disorder of the ischemic mitral valve (MV) is caused by the 3dimensional modification of the anteroposterior annular diameter, area/volume of tenting, and interpapillary muscle distance (IPMD). In extreme conditions of altered geometry (left ventricular [LV] end systolic volume/body surface area $/ \mathrm{mL} / \mathrm{m}^{2} \geq 65, \quad \mathrm{CL} \geq 12, \alpha^{2}$ angle $\geq 45^{\circ}$, IPMD $>20 \mathrm{~mm}$ ), the correction of all measures is needed to normalize function. ${ }^{3-6}$ The clinical benefit of concomitant MV repair in patients with ischemic etiology is through the optimal recovery of all ischemic regions to ensure favorable LV reverse remodeling over time. Reverse remodeling is improved by reducing myocardial scar tissue burden, explaining the rationale for complete revascularization of viable myocardium. ${ }^{4,5}$ Long-term survival outcomes and recurrence of mitral regurgitation (MR) are closely related. ${ }^{4,5}$

Persistent ischemic MR (IMR), especially with reduced LV ejection fraction, commonly results in LV dilatation, an independent risk factor for mortality. The exact biological and molecular events leading to adverse ventricular remodeling remain unclear. Adverse ventricular remodeling alters the geometrical configuration of left-sided chambers, resulting in MV distortion at the annular and subannular levels, promoting moderate-to-severe MR. As noted by Michler, ${ }^{6}$ the physiologic consequences of a severely dilated LV with depressed systolic function are severe functional MR and heart failure, which cannot be solved by combined reparative surgery. ${ }^{3-6}$

In the CTSN trial, $26.2 \%$ of patients who underwent restrictive mitral annuloplasty (RMA) did not have concomitant coronary artery bypass grafting, ${ }^{7}$ which offers a biological mechanism to explain the observed advantage in clinical outcomes of subvalvular repair in addition to RMA, matching those who had revascularization. ${ }^{1,4}$ In our randomized subvalvular repair trial, all patients had myocardial revascularization. ${ }^{3}$ Although revascularization is critical, we believe that criticisms of subvalvular repair procedures may derive from the presence of $22.5 \%$ of patients who have mild to moderate MR at a 5-year follow-up. ${ }^{3}$ This can be partially explained by large areas of scar tissue formation, dyskinesia, or basal aneurysms. Current prospective trials have not sufficiently highlighted improvements in postoperative tethering among patients with LV lateral wall dysfunction, persistent LV dyskinesis, severely altered LV sphericity, and predominant apical displacement of both leaflets due to symmetric tethering.

Numerous studies have focused on the degree of annular restriction by mitral annuloplasty given the reported risk of stenosis, systolic anterior motion, and recurrent MR in overcorrection or excessive undersizing. ${ }^{1-9}$ The anterior leaflet enlargement patch as performed by the authors is progressive $^{10}$ (Figure 1), provided that there is a marked reduction of tethering forces. ${ }^{11,12}$ The forces on the fibrous skeleton of the heart exerted by annular undersizing would counteract the displacement vectors relative to the LV dilation expected in these patients. The consequent imbalance of internal forces within the ventricle pushes the system toward a more unstable mechanical equilibrium, eventually leading to MR recurrence. ${ }^{11}$
A

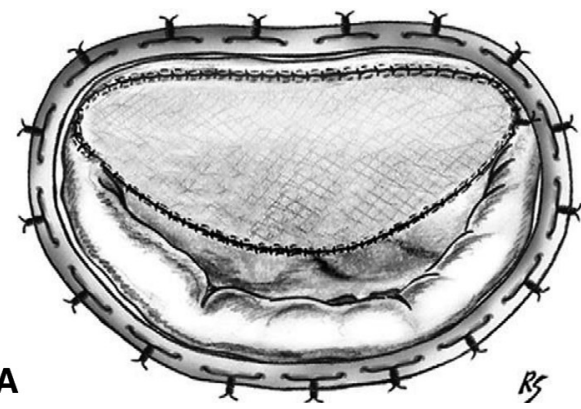

B

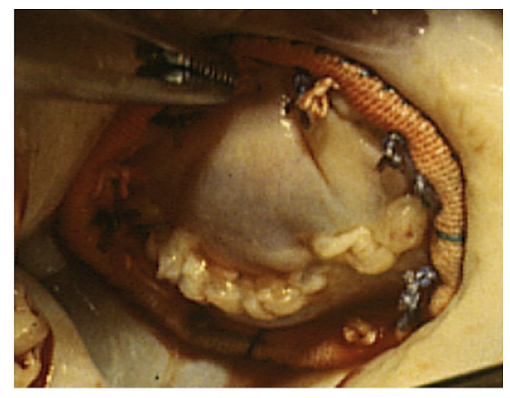

FIGURE 1. A, After detachment of the anterior mitral leaflet, the length of the incision is measured. The pericardium is sutured to the valve, and prosthetic ring annuloplasty is performed according to downsizing. B, Recipient of anterior leaflet enlargement patch.

\footnotetext{
The Editor welcomes submissions for possible publication in the Letters to the Editor section that consist of commentary on an article published in the Journal or other relevant issues. Authors should: • Include no more than 500 words of text, three authors, and five references. - Type with double-spacing. - See http://jtcs. ctsnetjournals.org/misc/ifora.shtml for detailed submission instructions. • Submit the letter electronically via jtcvs.editorialmanager.com. Letters commenting on an
}

article published in the JTCVS will be considered if they are received within 6 weeks of the time the article was published. Authors of the article being commented on will be given an opportunity of offer a timely response ( 2 weeks) to the letter. Authors of letters will be notified that the letter has been received. Unpublished letters cannot be returned. 
The authors reported no conflicts of interest.

The Journal policy requires editors and reviewers to disclose conflicts of interest and to decline handling or reviewing manuscripts for which they may have a conflict of interest. The editors and reviewers of this article have no conflicts of interest.

The use of subvalvular repair is associated with a significantly lower risk of exacerbating leaflet tethering caused by the anterior displacement of the posterior leaflet because of IPMD correction. This was more evident in patients with a lower LV end diastolic diameter $(<60 \mathrm{~mm})$ asymmetric tethering and a well-circumscribed infarct of the inferior myocardium. The papillary muscle approximation was not a significant effect modifier in $17 \%$ of patients with anterior myocardial infarctions and symmetrical patterns with predominantly severe apical tethering. ${ }^{5}$ Because the attrition rate of combined valvular and subvalvular surgery on asymmetric tethering, but not on symmetric tethering, increases with time, whether the clinical benefits seen at 5 years could increase with a longer follow-up period remains unknown.

Our recent meta-analysis highlighted the evidence of conflicting results between mitral repair surgery and the MitraClip procedure that adds a veil of mystery regarding the future of IMR treatment. The seemingly neglected importance of the subvalvular apparatus in this context may partially account for the poor results.

Francesco Nappi, $M D^{a}$

Sanjeet Singh Avtaar Singh, MRCS, PhD

${ }^{a}$ Department of Cardiac Surgery

Centre Cardiologique du Nord de Saint-Denis

Paris, France

${ }^{b}$ Department of Cardiothoracic Surgery

Golden Jubilee National Hospital

Glasgow, United Kingdom

\section{References}

1. Wan S, Hu J. Commentary: following the game-changers: are we on the right track now? J Thorac Cardiovasc Surg. June 29, 2020 [Epub ahead of print].

2. Nappi F, Antoniou GA, Nenna A, Michler R, Benedetto U, Avtaar Singh SS, et al Treatment options for ischemic mitral regurgitation: a meta-analysis. $J$ Thorac Cardiovasc Surg. May 27, 2020 [Epub ahead of print].

3. Nappi F, Lusini M, Spadaccio C, Nenna A, Covino E, Acar C, et al. Papillary muscle approximation versus restrictive annuloplasty alone for severe ischemic mitral regurgitation. J Am Coll Cardiol. 2016;67:2334-46.

4. Nappi F, Avtaar Singh SS, Padala M, Attias D, Nejjari M, Mihos CG, et al. The choice of treatment in ischemic mitral regurgitation with reduced left ventricular function. Ann Thorac Surg. 2019;108:1901-12.

5. Nappi F, Spadaccio C, Nenna A, Lusini M, Fraldi M, Acar C, et al. Is subvalvular repair worthwhile in severe ischemic mitral regurgitation? Subanalysis of the Papillary Muscle Approximation trial. J Thorac Cardiovasc Surg. 2017;153: 286-95.e2

6. Michler RE. Learning from controversy: management of severe ischemic mitral regurgitation at the time of CABG. Ann Thorac Surg. 2019;108:321-3.
7. Goldstein D, Moskowitz AJ, Gelijns AC, Ailawadi G, Parides MK, Perrault LP, et al. Two-year outcomes of surgical treatment of severe ischemic mitral regurgitation. N Engl J Med. 2016;374:344-53.

8. Kainuma S, Taniguchi K, Daimon T, Sakaguchi T, Funatsu T, Kondoh H, et al; Osaka Cardiovascular Surgery Research (OSCAR) Group. Does stringent restrictive annuloplasty for functional mitral regurgitation cause functional mitral stenosis and pulmonary hypertension? Circulation. 2011;124(11 Suppl):S97-106.

9. Kainuma S, Funatsu T, Kondoh H, Yokota T, Maeda S, Shuda Y, et al. Beneficial effects of restrictive annuloplasty on subvalvular geometry in patients with functional mitral regurgitation and advanced cardiomyopathy. J Thorac Cardiovasc Surg. 2018;156:630-8.e1.

10. Nappi F, Acar C. The use of anterior mitral leaflet augmentation with autologous pericardium. Why not? Ann Thorac Surg. December 18, 2020 [Epub ahead of print].

11. Nappi F, Carotenuto AR, Avtaar Singh SS, Mihos C, Fraldi M. Euler's elasticabased biomechanics of the papillary muscle approximation in ischemic mitral valve regurgitation: a simple 2D analytical model. Materials (Basel). 2019;12: 1518.

12. Nappi F, Spadaccio C, Chello M, Lusini M, Acar C. Double row of overlapping sutures for downsizing annuloplasty decreases the risk of residual regurgitation in ischaemic mitral valve repair. Eur J Cardiothorac Surg. 2016;49:1182-7.

https://doi.org/10.1016/j.jtcvs.2020.12.131

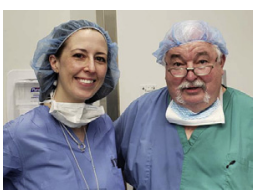

REPLY: CROSSING THE RUBICONVENTRICULAR DIMENSION CONTROLS THE ULTIMATE FATE OF ISCHEMIC MITRAL REGURGITATION PROCEDURES

Reply to the Editor:

In 49 BC, Julius Caesar defied the Roman Senate's ultimatum. Rather than disbanding his army, he marched them south across the Rubicon in northern Italy, initiating the civil war that ended the republic. Likewise, there is a ventricular dimension, which when crossed, determines the fate of ischemic mitral regurgitation (MR) repairs. In their letter to the Editor, Nappi and Singh ${ }^{1}$ address the complexity of this cardiac pathology.

There is a ventricular dimension after myocardial infarction (as yet not absolutely defined) in which the left ventricle (LV) geometry results in wall tensions where positive reverse remodeling after mitral repair is not possible. Rather, the unameliorated high wall strain in remote myocardium results in further injury to the LV. From the initial reports of Braun and colleagues ${ }^{2}$ through outcomes of the Cardiothoracic Surgery Network severe ischemic MR trial, ${ }^{3}$ large ventricular volumes after infarct have been associated with recurrent MR and poor outcomes. LV reshaping strategies ${ }^{4,5}$ have shown promise by decreasing remote myocardial wall tension and perhaps inhibiting remote apoptosis. ${ }^{6}$ The fault is not in our stars, but in the dilated ventricle.

Heidi B. Nafday, $M D$

Eugene A. Grossi, MD

Department of Cardiothoracic Surgery 